Bryant University

Bryant Digital Repository

3-28-2019

\title{
Dollar-Off or Percent-Off? Discount Framing, Construal Levels, and Advertising Appeals
}

Sukki Yoon

Bryant University, syoon@bryant.edu

Kacy Kim

Bryant University, kkim2@bryant.edu

Sujin Kim

University of Texas at Austin

Gabrielle Corner

Elon University

Follow this and additional works at: https://digitalcommons.bryant.edu/mark_jou

Part of the Marketing Commons

\section{Recommended Citation}

Yoon, Sukki; Kim, Kacy; Kim, Sujin; and Corner, Gabrielle, "Dollar-Off or Percent-Off? Discount Framing, Construal Levels, and Advertising Appeals" (2019). Marketing Department Journal Articles. Paper 108.

https://digitalcommons.bryant.edu/mark_jou/108

This Article is brought to you for free and open access by the Marketing Faculty Publications and Research at Bryant Digital Repository. It has been accepted for inclusion in Marketing Department Journal Articles by an authorized administrator of Bryant Digital Repository. For more information, please contact dcommons@bryant.edu. 


\title{
DOLLAR-OFF OR PERCENT-OFF? DISCOUNT FRAMING, CONSTRUAL LEVELS, AND ADVERTISING APPEALS
}

\author{
Kacy Kim, Ph.D. \\ Department of Marketing \\ Bryant University \\ kkim2@elon.edu \\ Sujin Kim \\ Stan Richards School of Advertising and Public Relations \\ Moody College of Communication \\ University of Texas at Austin \\ sujin.kim@utexas.edu \\ Gabrielle Corner \\ Department of Marketing \\ Elon University \\ gcorner@elon.edu \\ Sukki Yoon, Ph.D. \\ Department of Marketing \\ Bryant University \\ syoon@bryant.edu
}

Citation:

Kim, K., Kim, S., Corner, G., and Yoon, S. (forthcoming). Dollar-Off or Percent-Off? Discount Framing, Construal Levels, and Advertising Appeals, Journal of Promotion Management.

https://doi.org/10.1080/10496491.2019.1557808 


\title{
DOLLAR-OFF OR PERCENT-OFF? DISCOUNT FRAMING, CONSTRUAL LEVELS, AND ADVERTISING APPEALS
}

\begin{abstract}
In two studies, the authors reveal how consumers react to marketing messages when two commonly used promotional tactics — price discounts and advertising messages — are synergized. Building on construal level theory, Study 1 shows how dollar-off discount framings ("Buy 2, get $\$ 10$ off”) trigger low-level construal, while percent-off discount framings ("Buy 2, Get 50\% off") activate high-level construal. Study 2 demonstrates that congruent levels are matched when dollar-off discount appeals are paired with attribute appeals and when percent-off appeals are paired with benefit appeals, leading to more effective marketing communications.
\end{abstract}


Marketers often enhance advertising messages by offering price discounts paired with minimum purchase requirements ("X\% off all purchases if you spend at least \$Y") (Calson, 2017; Iranmanesh, Jayaraman, Imrie, \& Zailani, 2016; Yoon, Oh, Song, Kim, \& Kim, 2014; Yoon \& Vargas 2010; 2011). For example, a flyer from a local clothing shop might include a $\$ 10$ discount for purchasing two $\$ 10$ t-shirts either in a dollar-off format ("Buy 2, get $\$ 10$ off"), or in a percent-off format ("Buy 2, get 50\% off"). The two deals are economically identical: consumers in both scenarios pay the same price for the same products, but will they react more positively to one of the framings?

Building on construal level theory (CLT), we argue that consumer reactions to price discounts will vary depending on whether the advertising message highlights product attributes (e.g., "the shirt is made of $100 \%$ cotton") or product benefits (e.g., "the shirt makes you look intelligent"). That is, we expect that consumers would respond more positively to dollar-framed discounts when the advertising message emphasizes product attributes. In contrast, they would respond more positively to percentage-framed discounts when the ad message emphasizes product benefits.

The question is important to both marketers and consumers. Although discounts in either form are known to be effective (Suri, Monroe, \& Koc, 2013; Zhang \& Tsai, 2017; Zhao, Li, Teng, \& Lu, 2014), they are difficult to compare. Consumers routinely translate whether dollars or percentages are better deals, but they must use varying cognitive resources for the mentally challenging translation-calculation process regarding dollar-off or percent-off discounts (Chen, Marmorstein, Tsiros, \& Rao, 2012; Chen, Monroe, \& Lou, 1998; Delvecchio, Krishnan, \& Smith, 2007; Fogel \& Thornton, 2008; Lee, Deng, Unnava, \& Fujita, 2014; Yoon, 2013; Yoon et al., 2014). 
In this research, we contend that dollar discounts rather than percentage discounts are easier to process. Specifically, we build on construal level theory to argue that consumers feel psychologically nearer to the more easily processed dollar-off discounts. Despite significant theoretical and practical ramifications for marketers and consumers, surprisingly little attention has been paid to the joint effect of price discounts and advertising. To our best knowledge, no prior study has considered how advertising appeals and price discounts interactively shape consumer perceptions about the deal.

We attempt to fill the gap by proposing and investigating two hypotheses. First, we propose that consumers are likely to use low-level (high-level) construal when they encounter dollar-off (percent-off) discounts. Next, when those consumers view advertising messages that highlight product attributes (benefits), they will prefer dollar-off (percent-off) discounts.

In Study 1, we present empirical evidence for the theoretical argument explaining why dollar-off (percent-off) discounts might evoke low-level (high-level) construal. In Study 2, we demonstrate that consumers who have low-level (high-level) construal and view an advertisement that features attribute (benefit) ad appeals will prefer dollar-off (percent-off) discounts.

\section{THEORETICAL BACKGROUND}

\section{Construal Level Theory}

Construal Level Theory (CLT) explains that mental construal levels are based on psychological distance (Dhar \& Kim, 2007; Lee \& Ariely, 2006; Lee et al., 2014; Trope \& Liberman, 2010). Psychological distance is egocentric: its reference point is the self in the here and now; individuals view objects in relation to their distance from the self in time (tomorrow vs. 
next year), in space (neighborhood vs. another country), in social distance (us vs. them), and in hypothetical terms (likely vs. unlikely) (Trope \& Liberman 2003; 2010).

When individuals perceive objects and events as psychologically imminent, they are likely to focus on details about the event, to construe it in concrete, low-level terms regarding how the event will happen. When they perceive objects and events as psychologically distant, they tend to construe the event schematically, abstractly, in high-level terms regarding why the event will happen (Liberman, Sagristano, \& Trope, 2002).

For example, when you are planning a family vacation for next year, you will approach the event with high-level, abstract construal, focusing on why you will enjoy the vacation (e.g., "our family will spend quality time together"), but as the vacation becomes imminent, you are likely to shift to a low-level, concrete construal focused on the details of how you will enjoy the vacation (e.g., "we will dine at the sushi restaurant on the beach") (Trope \& Liberman, 2010).

\section{Processing Fluency}

Thus psychological distance reflects how far individuals perceive a stimulus to be from their psychological space. Distance calculations are spontaneous, even without explicit instruction (Alter \& Oppenheimer, 2008; Bar-Anan, Liberman, \& Trope, 2006; Shirai, 2015; Yoon, Kim, Beltis, Logan, \& Subramanian, 2018). CLT has been applied to diverse research contexts such as sensory effects on brand extensions (e.g., Amit, Algom, \& Trope, 2009; Lee et al., 2014), language choices for marketing communication (Semin \& Smith, 1999), store location choices (Khan, Zhu, \& Kalra, 2011), banner ad selection (Jeong \& King, 2010) and fluency of information processing (Alter \& Oppenheimer, 2008).

Processing fluency is the metacognitive experience of ease associated with a cognitive process (Alter \& Oppenheimer, 2008). When people experience disfluency, such as difficulty in 
reading (Alter \& Oppenheimer, 2008; Oh, Yoon, \& Vargas, in press), or causal uncertainty about an event (Namkoong \& Henderson, 2014; Rim, Hansen, \& Trop, 2013), they are likely to interpret situations abstractly and perceive them as distant. Processing fluency links with closeness, while processing disfluency links with distance; that is, fluency has bidirectional associations with psychological proximity (Oh et al., in press; Shah, \& Oppenheimer, 2008). In this research, we suggest that individuals will perceive that a psychologically close (distant) stimulus is easy (difficult) to process.

Consequently, when consumers analyze price discounts, they would perceive the dollaroff (percent-off) discounts to be relatively close (distant), concrete (abstract), and easy (difficult) to process, which may affect their overall judgment of the marketing message.

\section{Psychological Distance in Discount Framing}

Sales tend to increase when consumers receive free bonus packs giving them additional product for the same price, but not when identical savings come in the form of a percentage off yielding the same amount of product at a lower price (Chen et al., 2012). Thus the absolute amount of savings has different impacts on consumer reactions to deals. Similarly, many factors such as baseline price or familiarity with the product influence preferences for dollar versus percent discounts (Aspara, Jaakko, \& Chakravarti, 2015; Chen et al., 2012; Yoon et al., 2014). Furthermore, humans are evolutionarily wired to understand simple and easy whole numbers better than they understand complex percentages, decimals, and fractions (Chen et al., 2012). We contend that complexity is another dimension of psychological distance manifested via dollar-off or percent-off discount framing. Thus we hypothesize:

H1a: Dollar-off discounts will appear psychologically proximal.

H2b: Percentage-off discounts will appear psychologically distal. 


\section{Congruency between Discount Framing and Advertising Appeals}

Consumers often make purchase decisions according to product features. In terms of CLT, when advertising messages use concrete terms, consumers tend to focus on product feasibility such as attributes or prices; when advertising messages use abstract terms, consumers tend to focus on product desirability such as benefits or quality (Lee et al., 2018a; 2018b; Liviatan, Trope, and \& Liberman, 2008). In other words, when consumers are psychologically near a decision (e.g., "I will purchase a flight ticket tomorrow"), they may focus on detailed product features such as price (e.g., Liviatan et al., 2008), but when they are psychologically distant from a decision (e.g., "I will purchase a flight ticket next year"), they may focus on abstract product features such as quality (Dhar \& Kim, 2007).

Neither attribute nor benefit appeals are necessarily preferable, but claims should be congruent with the psychological distance evoked; that is, when consumers see ads from a far psychological distance, the message should emphasize "core central features" (e.g., benefit appeals) and when consumers view ads from a near psychological distance, messages should emphasize "secondary peripheral features" (e.g., attribute appeals) (Dhar \& Kim, 2007).

The concept of benefits versus attributes aligns with the idea of feasibility versus desirability (Lee et al., 2018a; 2018b; Liberman \& Trope, 1998). Feasibility is related to means and goal progress, such as how many hours of study will be required to succeed in a class, and is associated with low-level construal. In contrast, desirability is related to goal commitment such as doing well in school and is associated with high-level construal (Lee et al., 2018a; 2018b). Building on Dhar and Kim's (2007) logic, we expect that our study participants will be more receptive to marketing messages when we frame price discounts to be congruent with advertising messages. 
From the CLT perspective, as predicted in H1, dollar-off discounts are proximal; percent-off promotions are distal. Therefore, advertising messages that emphasize product attributes will evoke low-level construal and will be congruent with dollar-off discounts, whereas advertising messages that emphasize product benefits will evoke high-level construal and will be congruent with percent-off discounts.

Which framing will create more positive responses? We argue that marketing communications will be more effective when we match an attribute appeal—"the shirt is made of $100 \%$ cotton" - with the dollar-off discount "Buy 2 , get $\$ 10$ off." Similarly, we predict that participants will respond more positively when we match the benefit appeal- "the shirt makes you look intelligent"-with the percent-off discount "Buy 2, get 50\% off." Thus, we predict:

H2a: Dollar-off discounts will be more effective for attribute appeals.

H2b: Percent-off discounts will be more effective for benefit appeals.

\section{STUDY 1}

We conducted Study 1 to test H1. To measure whether participants tend to construe behaviors in high- or low-level terms, we adopted the classic Behavioral Identification Form (BIF; Vallacher \& Wegner, 1989) expecting that an ad featuring dollar-off discounts would induce procedural mind-sets dominated by low-level construal (H1a), whereas an ad featuring percent-off discounts would induce procedural mindsets dominated by high-level construal (H1b).

\section{Method}

We recruited 125 undergraduate students from a northeastern private university. The study used a one-factor design, with discount framing (dollar-off vs. percent-off) serving as a 
between-subjects factor. The data were collected via an online survey.

We created two print ads for a fictitious clothing brand called The Corner Shirt. The ad features a plain white t-shirt against a black background. One ad indicates a dollar-off discount for two $\$ 10$ t-shirts: "Buy 2, get $\$ 10$ off"; the other indicates a percent-off discount: "Buy 2, get $50 \%$ off."

After viewing the ad, participants completed a task adapted from the classic BIF (Vallacher \& Wegner, 1989). First they indicated which of two descriptions of target behaviors they preferred. For example, in considering a clothes-washing task, they indicated whether washing clothes involves putting clothes into the machine (low-level construal) or removing odors from clothes (high-level construal). Participants in concrete modes are more likely to choose behaviors that highlight means; those in abstract thinking modes are expected to choose behaviors that highlight ends. Following Lee et al. (2014), we chose twelve of the original BIF items (see Table 1). Preferences for the concrete, low-level identification were scored 0 , and preferences for the abstract, high-level identification were scored 1 . We summed the scores to create an abstraction index from 0 to 12 with higher scores indicating higher-level construal.

\section{Results}

As predicted, discount framing evoked significant effects $(t(123)=2.87, p<.01)$. Participants who viewed the dollar-off discount preferred more concrete behavioral descriptions $\left(\mathrm{M}_{\mathrm{dollar}}=6.00\right)$, while those who saw the percent-off discount selected the more abstract behavioral descriptions $\left(\mathrm{M}_{\text {percent }}=7.28\right)$. Table 1 describes choice probabilities for the twelve items as a function of condition.

$<$ Insert Table 1 about here $>$ 


\section{Discussion}

Study 1 tested our baseline supposition that discount framing affects construal level. Participants who viewed the ad featuring a dollar-off discount tended toward concrete low-level construal for interpreting the BIF-suggested behaviors. In contrast, participants who viewed a percent-off discount interpreted the behaviors according to an abstract high-level construal. For example, when participants considered the act of picking an apple, those who had low-level construal focused on the concrete action of pulling an apple off a branch, while participants primed with high-level construal focused on the higher-level purpose of gathering nourishment.

Thus dollar-off discounts activate low-level construal, while percent-off discounts activate high-level construal. Will consumers be more or less receptive to these two discount framings, depending on the advertising appeals that correspond to low- and high-level construals? Study 2 addresses this question.

\section{STUDY 2}

We conducted Study 2 to test H2. We expected that participants who viewed an ad message using attribute appeals would favor a dollar-off discount. In contrast, participants who saw an ad using benefit appeals would favor a percent-off discount.

\section{Method}

We recruited 95 undergraduate students from a northeastern private university. The study used a 2 (discount framing: dollar- vs. percent-off) x 2 (ad appeal: attribute vs. benefit appeals) between-subjects factorial design. The data were collected via an online survey.

We created four print advertisements with simple designs similar to the ones used in Study 1 (see Appendix for the stimuli). As in Study 1, the ads featured a fictional brand, The 
Corner Shirt, selling t-shirts for $\$ 10$. The ad features a plain white t-shirt against a black background. For the dollar-off discount, the ad copy states "Buy 4 , get $\$ 10$ off." For the percentoff discount, the ad copy states "Buy 4 , get $25 \%$ off." The two discounts are equivalent: the final price after the discount would be $\$ 30$ for both conditions.

In addition, we manipulated attribute versus benefit appeals. For the attribute appeal condition, the ad copy states "We know you've been looking for the best shirt out there. We have the answer you need. Our NEW shirt is pre-shrunk, pre-washed and 100\% cotton." For the benefit appeal, the ad copy states "We know you've been looking for the best shirt out there. We have the answer you need. Our NEW shirt makes you more attractive, intelligent and confident." Participants were randomly assigned to one of the four conditions at the beginning of the survey.

Participants answered questions about their attitudes toward the advertisement (good, appealing, favorable, pleasant, positive, attractive, amusing, likeable, effective) on a seven-point Likert type scale $(1=$ strongly disagree, 7 = strongly agree; Lee and Aaker 2004; MacKenzie and Lutz 1989). The nine items were averaged to form an index for attitude toward advertising: a higher score indicated a more positive attitude $(\alpha=.87)$.

\section{Results}

Discount framing significantly interacted with ad appeal to affect attitudes toward advertising $(F(1,91)=12.62, p<.01)$. As Figure 1 shows, participants who viewed attributeappeal messages favored the ad with the dollar-off discount $(t(46)=2.73, p<.01)\left(\mathrm{M}_{\mathrm{dollar}}=4.03\right)$ over the ad with the percent-off discount $\left(\mathrm{M}_{\text {percent }}=3.26\right)$. In contrast, those who viewed benefitappeal ad messages favored the ad with the percent-off discount $(t(45)=-2.63, p<.05)\left(\mathrm{M}_{\text {percent }}\right.$ $=3.88)$ over the ad with the dollar-off discount $\left(\mathrm{M}_{\mathrm{dollar}}=3.18\right)$.

$<$ Insert Figure 1 about here $>$ 


\section{Discussion}

Study 2 extended Study 1 by showing effects of congruency when discount framing was matched with advertising messages. Attribute appeals were associated with low-level construal. Therefore, dollar-off discounts enhanced the overall effectiveness of advertising that highlighted product attributes. In contrast, benefit appeals were associated with high-level construal. Therefore percent-off discounts enhanced the overall effectiveness of advertising that highlighted product benefits.

\section{GENERAL DISCUSSION}

The results of two experimental studies show how two commonly used promotional tactics — price discounts and advertising — should be synergized to enhance consumer acceptance of marketing messages. Building on construal level theory, we show that congruency between price discount framing and advertising appeals enhances the overall effect of marketing communications. Specifically, in Study 1, we demonstrate that a dollar-off discount triggers lowlevel construal; a percent-off discount activates high-level construal. In Study 2, we match lowlevel construal advertising messages featuring attribute appeals with low-level discounts featuring dollar-off discounts. We also match high-level construal advertising messages featuring benefit appeals with high-level discounts featuring percentage off. When the promotions had congruent (incongruent) construal levels, study participants had relatively positive (negative) responses.

Our findings add to the promotion literature by demonstrating that promotional activities must be coordinated to optimize message receptivity. The principle of integrated marketing communications (IMC) emphasizes the benefits of synergy across multiple media (Schultz, 1992; Zvobgo \& Melewar, 2011). We show that strategic integration also happens at 
psychological levels. The IMC literature has disproportionally focused on the need for consistent message contents across media, but more scholarly attention is needed to observe psychological congruency across promotional platforms (e.g., McKay-Nesbitt \& Yoon, 2015). For example, the literature regarding gain/loss message framing (e.g., Baek \& Yoon, 2017) suggests that consumers might form different perceptions toward addition-framed discounts ("Buy 2, get 1 free") than toward subtraction-framed discounts (“Get 3, pay for 2"). Advertising effects are likely to be enhanced if addition-framed (subtraction-framed) discounts are matched to gainframed (loss-framed) advertising messages. For example, gain-framed advertising messages would urge consumers to consider the benefits of using the product, while loss-framed advertising messages would warn about the costs of failing to use the product.

We operationalized construal level by comparing dollar-framed with percent-framed discounts, and observed how the discounts interacted with attribute and benefit advertising appeals. However, the theory of construal level is open to alternative operationalizations. For example, Lee et al. (2018) introduced feasibility versus desirability CLT message framing in an anti-smoking campaign context. Future research should observe how different message framings on various communication platforms can strengthen or weaken the overarching theme of IMC.

One future research approach might apply the current conceptualization to other dimensions of psychological distance. For example, to conceptually replicate the congruency effect in the temporal dimension, researchers might give the price promotion an expiration date so that study participants have two discount windows. The end-of-week deal might be offered "for all purchases made by the end of this week!" The end-of-year deal might be offered "for all purchases made by the end of this year!" According to our theorization, dollar-off discounts should be more effective fits with end-of-week discounts, but percent-off discounts should be 
more effective with end-of-year discounts.

In this study, we assumed that processing complexity is another dimension of psychological distance, but we need additional validating evidence. Overall, our findings have straightforward implications regarding how promotional messages should be strategically orchestrated. We recommend that marketers who want to highlight the attributes of products and services will be more successful by using dollar-off discounts. In contrast, percent-off discounts will be more effective when marketers emphasize the end benefits of products and services. 


\section{RERERENCES}

Alter, A. L., \& Oppenheimer, D. M. (2008). Effects of fluency on psychological distance and mental construal (or why New York is a large city, but New York is a civilized jungle). Psychological Science, 19(2), 161-167.

Amit, E., Algom, D., \& Trope, Y. (2009). Distance-dependent processing of pictures and words. Journal of Experimental Psychology: General, 138(3), 400.

Aspara, J., Chakravarti, A., \& Hoffmann, A. O. (2015). Focal versus background goals in consumer financial decision-making: Trading off financial returns for self-expression? European Journal of Marketing, 49(7/8), 1114-1138.

Baek, T. H., \& Yoon, S. (2017). Guilt and shame: Environmental message framing effects. Journal of Advertising, 46(3), 440-453.

Bar-Anan, Y., Liberman, N., \& Trope, Y. (2006). The association between psychological distance and construal level: evidence from an implicit association test. Journal of Experimental Psychology: General, 135(4), 609.

Carlson, J. (2017). A content analysis of bonus pack promotions. Journal of Promotion Management, 23(6), 930-950.

Chen, G. R. (2013). Nonlinear relationship between frequent price discounts and consumers' price sensitivity. Journal of Promotion Management, 19(1), 76-85.

Chen, H., Marmorstein, H., Tsiros, M., \& Rao, A. R. (2012). When more is less: The impact of base value neglect on consumer preferences for bonus packs over price discounts. Journal of Marketing, 76(4), 64-77.

Chen, S. F. S., Monroe, K. B., \& Lou, Y. C. (1998). The effects of framing price promotion messages on consumers' perceptions and purchase intentions. Journal of retailing, 74(3), $353-372$.

DelVecchio, D., Krishnan, H. S., \& Smith, D. C. (2007). Cents or percent? The effects of promotion framing on price expectations and choice. Journal of Marketing, 71(3), 158170.

Dhar, R., \& Kim, E. Y. (2007). Seeing the forest or the trees: Implications of construal level theory for consumer choice. Journal of Consumer Psychology, 17(2), 96-100.

Fogel, S. O. C., \& Thornton, C. G. (2008). What a hassle! Consumer perceptions of costs associated with sales promotions. Journal of Promotion Management, 14(1-2), 31-44.

Iranmanesh, M., Jayaraman, K., Imrie, B. C., \& Zailani, S. (2016). Promoting Products Through Volume Discount: Evidence from Malaysia. Journal of Promotion Management, 22(1), 


\section{1-88. https://doi-org.ezproxy.lib.utexas.edu/10.1080/10496491.2015.1107009}

Jeong, Y., \& King, C. M. (2010). Impacts of website context relevance on banner advertisement effectiveness. Journal of Promotion Management, 16(3), 247-264.

Khan, U., Zhu, M., \& Kalra, A. (2011). When trade-offs matter: The effect of choice construal on context effects. Journal of Marketing Research, 48(1), 62-71.

Lee, A. Y., \& Aaker, J. L. (2004). Bringing the frame into focus: the influence of regulatory fit on processing fluency and persuasion. Journal of personality and social psychology, 86(2), 205.

Lee, L., \& Ariely, D. (2006). Shopping goals, goal concreteness, and conditional promotions. Journal of Consumer Research, 33(1), 60-70.

Lee, H., Deng, X., Unnava, H. R., \& Fujita, K. (2014). Monochrome forests and colorful trees: The effect of black-and-white versus color imagery on construal level. Journal of Consumer Research, 41(4), 1015-1032.

Lee, Y., Yoon, S., Chun, S., Park, C., \& Kim, K. (2018). How liberals and conservatives respond to feasibility and desirability appeals in anti-tobacco campaigns. Asian Journal of Communication, 1-18.

Lee, Y., Yoon, S., Lee, Y. W., \& Royne, M. B. (2018). How Liberals and Conservatives Respond to Equality-Based and Proportionality-Based Rewards in Charity Advertising. Journal of Public Policy \& Marketing, 37(1), 108-118.

Liberman, N., Sagristano, M. D., \& Trope, Y. (2002). The effect of temporal distance on level of mental construal. Journal of experimental social psychology, 38(6), 523-534.

Liberman, N., \& Trope, Y. (1998). The role of feasibility and desirability considerations in near and distant future decisions: A test of temporal construal theory. Journal of personality and social psychology, 75(1), 5.

Liviatan, I., Trope, Y., \& Liberman, N. (2008). Interpersonal similarity as a social distance dimension: Implications for perception of others' actions. Journal of experimental social psychology, 44(5), 1256-1269.

MacKenzie, S. B., \& Lutz, R. J. (1989). An empirical examination of the structural antecedents of attitude toward the ad in an advertising pretesting context. The Journal of Marketing, 48-65.

McKay-Nesbitt, J., \& Yoon, S. (2015). Social marketing communication messages: How congruence between source and content influences physical activity attitudes. Journal of Social Marketing, 5(1), 40-55. 
Namkoong, J. E., \& Henderson, M. D. (2014). It's simple and I know it! Abstract construals reduce causal uncertainty. Social Psychological and Personality Science, 5(3), 352-359.

Oh, S., Yoon, S., \& Vargas, P. P., (in press), “In-Depth” Incidental Exposure: How Processing Difficulty and Processing Style Affect Evaluations of Transparent Overlay Images, European Journal of Marketing, Accepted for publication.

Schultz, D. E. (1992). Integrated marketing communications. Journal of Promotion Management, $1(1), 99-104$.

Semin, G. R., \& Smith, E. R. (1999). Revisiting the past and back to the future: Memory systems and the linguistic representation of social events. Journal of Personality and Social Psychology, 76(6), 877.

Shah, A. K., \& Oppenheimer, D. M. (2008). Heuristics made easy: An effort-reduction framework. Psychological bulletin, 134(2), 207.

Shirai, M. (2015). Impact of "High Quality, Low Price" appeal on consumer evaluations. Journal of Promotion Management, 21(6), 776-797.

Suri, R., Monroe, K. B., \& Koc, U. (2013). Math anxiety and its effects on consumers' preference for price promotion formats. Journal of the Academy of Marketing Science, 41(3), 271-282.

Trope, Y., \& Liberman, N. (2003). Temporal construal. Psychological review, 110(3), 403.

Trope, Y., \& Liberman, N. (2010). Construal-level theory of psychological distance. Psychological review, 117(2), 440.

Rim, S., Hansen, J., \& Trope, Y. (2013). What happens why? Psychological distance and focusing on causes versus consequences of events. Journal of Personality and Social Psychology, 104(3), 457.

Vallacher, R. R., \& Wegner, D. M. (1989). Levels of personal agency: Individual variation in action identification. Journal of Personality and Social psychology, 57(4), 660.

Yoon, S. (2013). Do negative consumption experiences hurt manufacturers or retailers? The influence of reasoning style on consumer blame attributions and purchase intention. Psychology \& Marketing, 30(7), 555-565.

Yoon, S., Kim, K., Beltis, A. J., Logan, J., \& Subramanian, G. (in press), Red Sox versus Yankees: Sports Team Rivalry, Sports Symbols, and Distance Performance, Journal of Global Sport Management, Accepted for publication.

Yoon, S., Oh, S., Song, S., Kim, K., \& Kim, Y. (2014). Higher quality or lower price? How value-increasing promotions affect retailer reputation via perceived value. Journal of Business Research, 67(10), 2088-2096. 
Yoon, S., \& Vargas, P. T. (2010). Feeling happier when paying more: dysfunctional counterfactual thinking in consumer affect. Psychology \& Marketing, 27(12), 1075-1100.

Yoon, S., \& Vargas, P. (2011). "No More" leads to "Want More," but "No Less" leads to "Want Less": Consumers' counterfactual thinking when faced with quantity restriction discounts. Journal of Consumer Behaviour, 10(2), 93-101.

Zhang, J., \& Tsai, W. S. (2017). What promotes online group-buying? A cross-cultural comparison study between China and the United States. Journal of Promotion Management, 23(5), 748-768.

Zhao, G., Li, W., Teng, L., \& Lu, T. (2014). Moderating role of consumer self-concept on the effectiveness of two nostalgia appeals. Journal of Promotion Management, 20(1), 1-19.

Zvobgo, M., \& Melewar, T. C. (2011). Drivers of globally integrated marketing communications: A review of literature and research propositions. Journal of Promotion Management, $17(1), 1-20$. 
TABLE AND FIGURE

Table 1. Behavior Identification Form Results (Study 1)

\begin{tabular}{|c|c|c|}
\hline Behavior & $\begin{array}{l}\text { Two Interpretations of Behavior } \\
\text { (High-level vs. Low-level) }\end{array}$ & $\begin{array}{l}\text { \% Choosing High-level } \\
\text { (\% off vs. \$ off) }\end{array}$ \\
\hline Joining the Army & Helping the nation's defense vs. signing up & $86 \%$ vs. $70 \%$ \\
\hline Washing clothes & $\begin{array}{l}\text { Removing odors from clothes vs. putting clothes in } \\
\text { the machine }\end{array}$ & $77 \%$ vs. $68 \%$ \\
\hline Picking an apple & $\begin{array}{l}\text { Getting something to eat vs. pulling an apple off a } \\
\text { branch }\end{array}$ & $50 \%$ vs. $44 \%$ \\
\hline Painting a room & $\begin{array}{l}\text { Making the room look fresh vs. applying brush } \\
\text { strokes }\end{array}$ & $68 \%$ vs. $59 \%$ \\
\hline Climbing a tree & Getting a good view vs. holding onto branches & $61 \%$ vs. $42 \%$ \\
\hline Filling out a personality test & Revealing what you're like vs. answering questions & $62 \%$ vs. $56 \%$ \\
\hline Resisting temptation & Showing moral courage vs. saying "no" & $65 \%$ vs. $46 \%$ \\
\hline Eating & Getting nutrition vs. chewing and swallowing & $74 \%$ vs. $59 \%$ \\
\hline Growing a garden & Getting fresh vegetables vs. planting seeds & $52 \%$ vs. $46 \%$ \\
\hline Having a cavity filled & Protecting your teeth vs. going to the dentist & $52 \%$ vs. $37 \%$ \\
\hline Talking to a child & Teaching a child something vs. using simple words & $55 \%$ vs. $51 \%$ \\
\hline Pushing a doorbell & Seeing if someone's home vs. moving a finger & $82 \%$ vs. $73 \%$ \\
\hline
\end{tabular}

Figure 1. Discount Framing X Ad Appeal Interaction (Study 2)

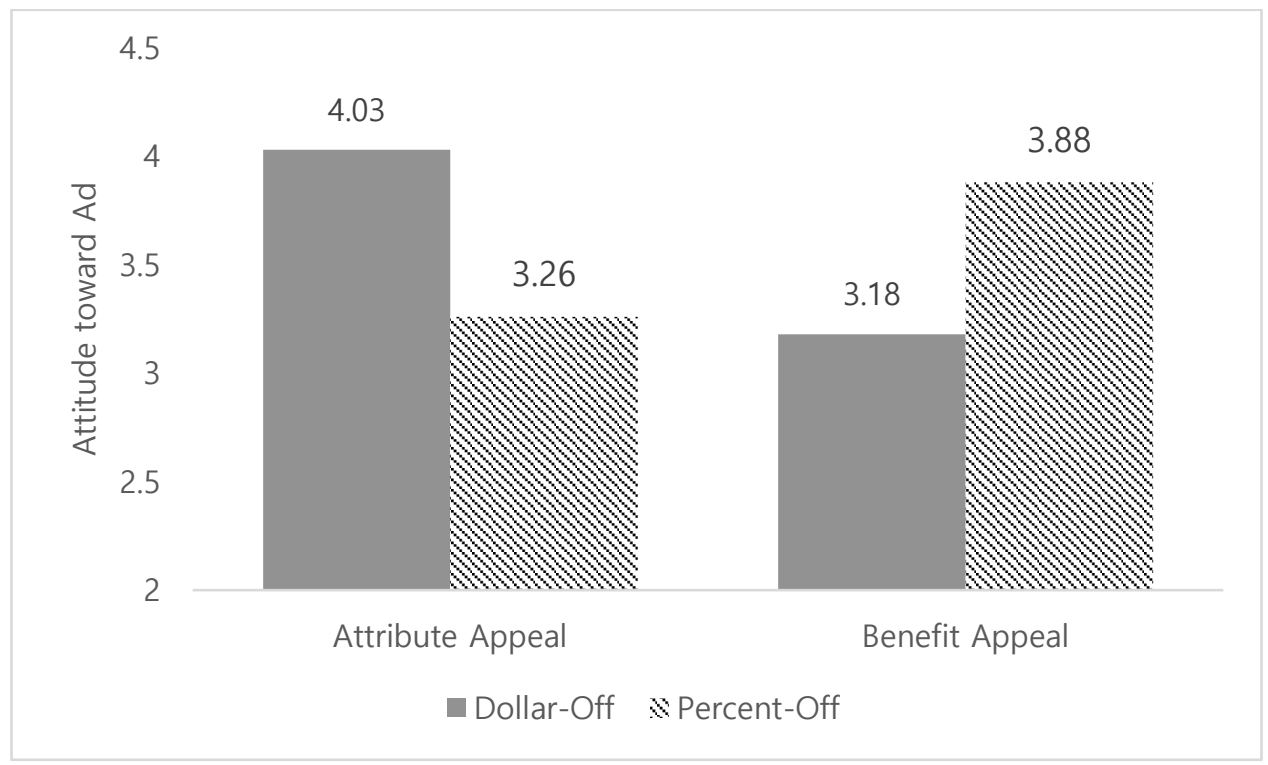




\section{APPENDIX}

Dollar-attribute condition

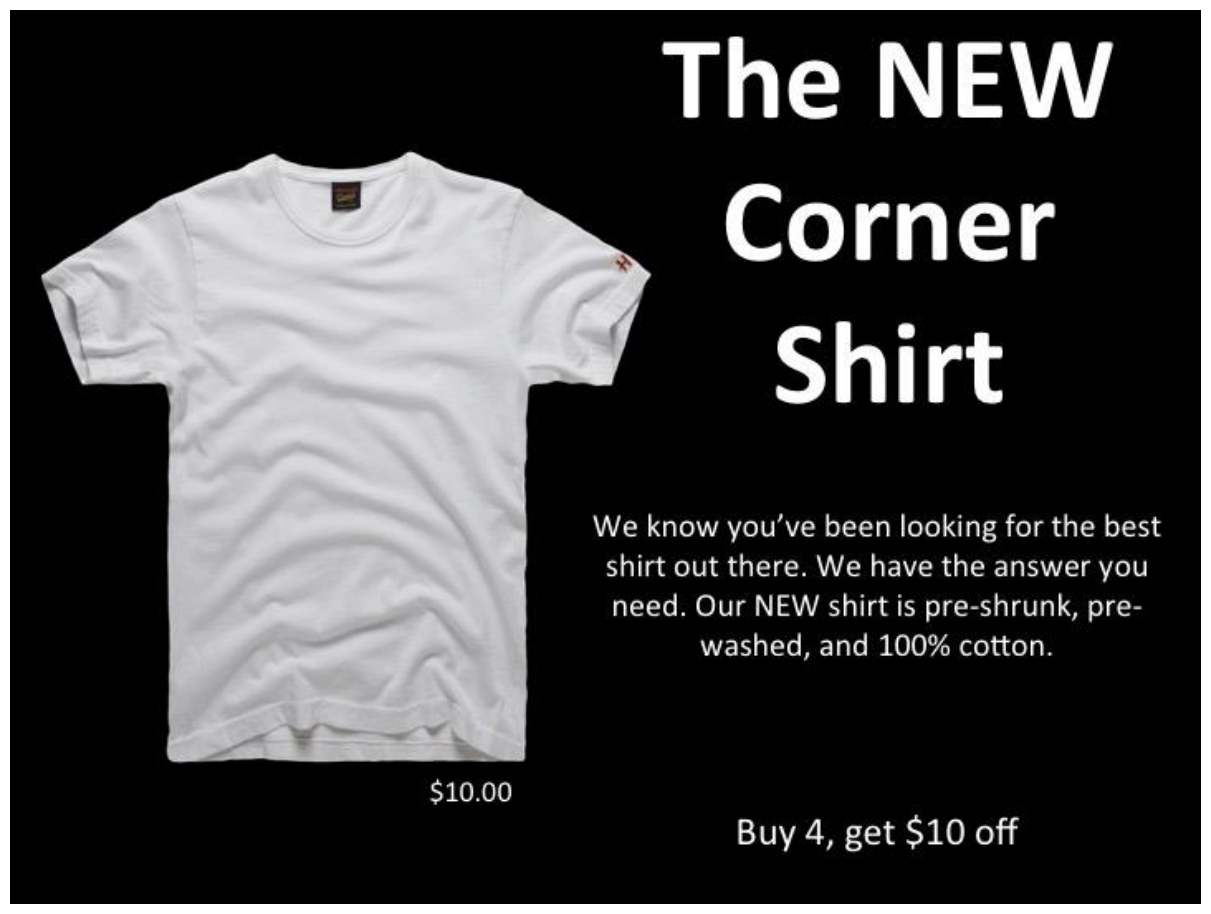

Dollar-benefit condition




Percent-attribute condition

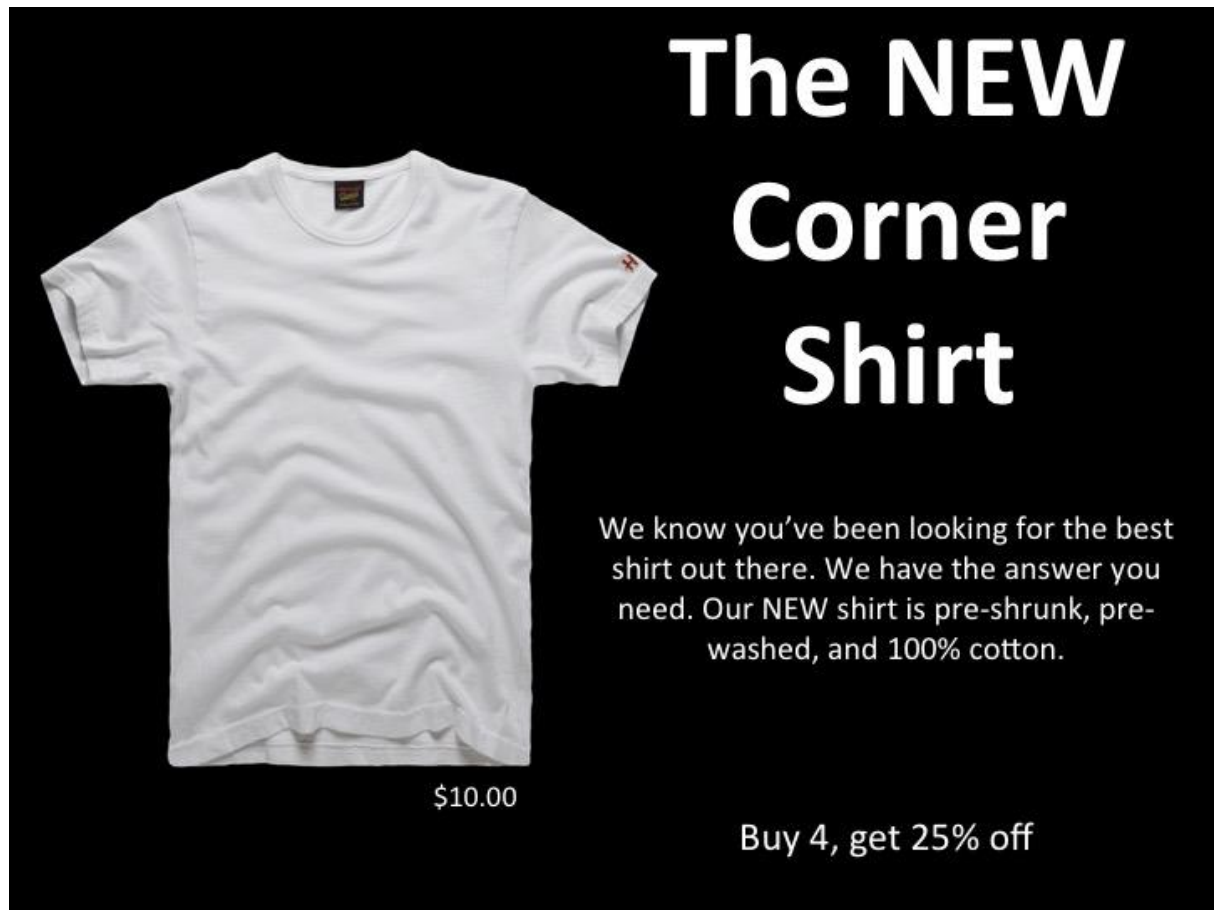

Percent-benefit condition

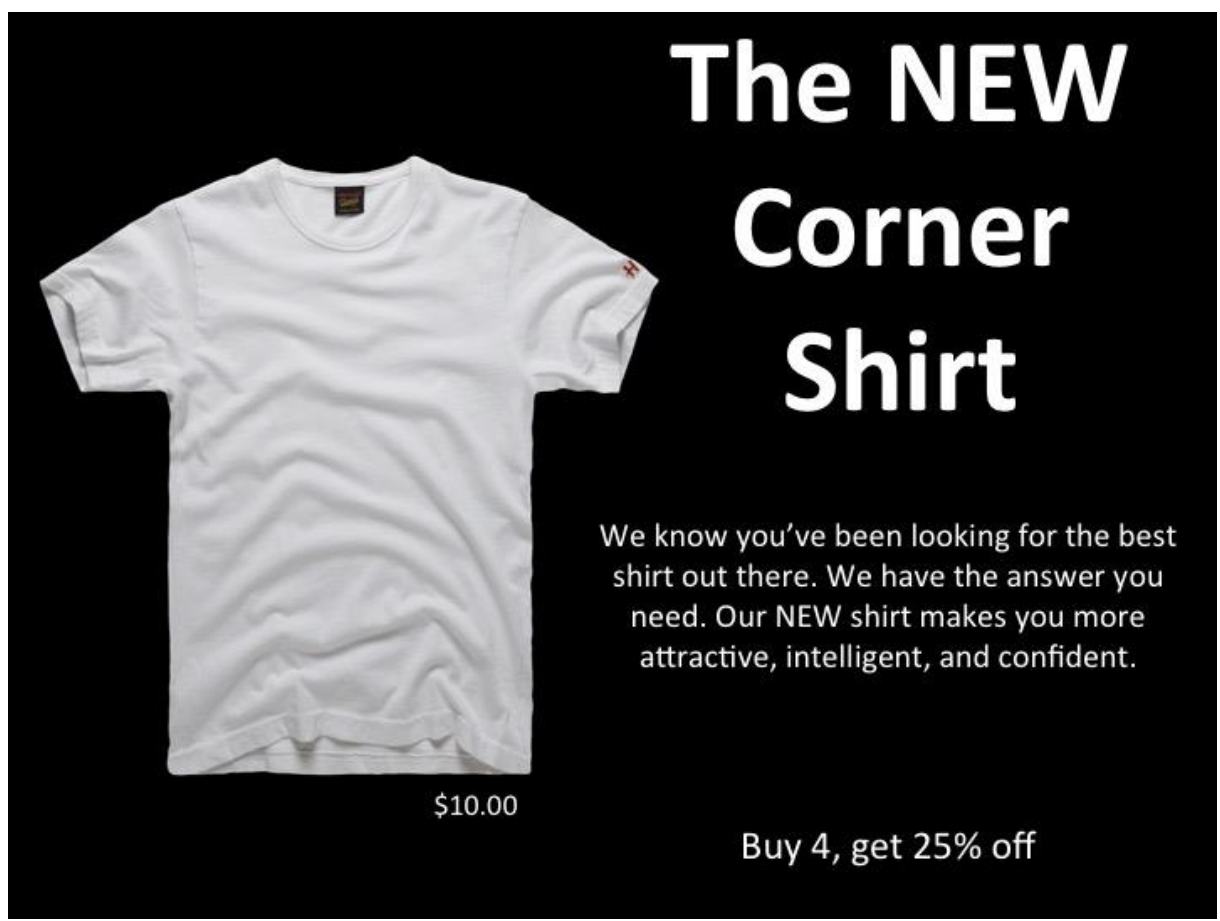

